\title{
The role of FoxO4 in the relationship between alcohol-induced intestinal barrier dysfunction and liver injury
}

\author{
BING CHANG ${ }^{1}$, LIXUAN SANG $^{2}$, YING WANG $^{1}$, JING TONG $^{1}$ and BINGYUAN WANG ${ }^{1}$ \\ Departments of ${ }^{1}$ Gastroenterology and ${ }^{2}$ Cadre Ward II, The First Affiliated Hospital \\ of China Medical University, Shenyang, Liaoning 110001, P.R. China
}

Received August 6, 2012; Accepted December 11, 2012

DOI: $10.3892 /$ ijmm.2013.1229

\begin{abstract}
Forkhead box 'Other' (FoxO) proteins, a subgroup of the Forkhead transcription factor family, play an important role in mediating the effects of insulin and growth factors on diverse physiological functions. In this study, we investigated the role of FoxO4 in the relationship between alcohol liver disease and intestinal barrier dysfunction using an animal model. Six to eight-week-old male WT rats were divided into eight groups. They were separately administered corn starch dissolved in PBS; 40\% alcohol (5 g/kg body weight) through stomach feeding every $12 \mathrm{~h} /$ time, three times in total; tumor necrosis factor $\alpha(\mathrm{TNF} \alpha)(10 \mu \mathrm{g} / \mathrm{kg})$ injected intraperitoneally $30 \mathrm{~min}$ before alcohol administration; wortmannin $(1.4 \mathrm{mg} /$ $\mathrm{kg}) 30 \mathrm{~min}$ before alcohol administration; IGF-1 $(0.2 \mathrm{mg} / \mathrm{kg})$ $30 \mathrm{~min}$ before alcohol administration; anti-TNF $\alpha(5 \mathrm{mg} / \mathrm{kg})$ injected intravenously $30 \mathrm{~min}$ before alcohol administration. In addition, two placebo groups were treated with PBS either intraperitoneally or intravenously prior to alcohol administration. $\mathrm{TNF} \alpha$ and endotoxin in plasma were measured by ELISA and Tachypleus Amebocye Lysate assays. Immunohistochemistry and western blotting were used to identify the mechanisms of FoxO4 action in regulating epithelial permeability. Furthermore, electron microscopy, reverse transcriptionpolymerase chain reaction and western blotting were used to examine the expression of tight junction proteins and nuclear factor- $\kappa \mathrm{B}(\mathrm{NF}-\kappa \mathrm{B})$. Compared with the control group, $\mathrm{TNF} \alpha$ in the alcohol group was significantly higher. TNF $\alpha$ could induce FoxO4 phosphorylation; p-FoxO4 was limited into the cytoplasm and inactivated; inactive FoxO4 which was in high levels lost the ability to suppress $N F-\kappa B$. Therefore, the expression of $\mathrm{NF}-\kappa \mathrm{B}$ was increased and it downregulated tight junction protein (including ZO-1 and occludin) expression,
\end{abstract}

Correspondence to: Professor Bingyuan Wang, Department of Gastroenterology, The First Affiliated Hospital of China Medical University, 155 Nanjing North Street, Heping District, Shenyang, Liaoning 110001, P.R. China

E-mail: cb000216@163.com

Key words: alcoholic liver disease, intestinal barrier, tumor necrosis factor $\alpha$, FoxO4, nuclear factor- $\kappa \mathrm{B}$, tight junctions and increased epithelial permeability. As a result, intestinal bacteria grew excessively, endotoxin was released into the portal circulation and liver injury deteriorated. These results indicate that a complex network of mechanisms is involved in the beneficial effects of FoxO4 in epithelial barrier dysfunction. TNF $\alpha$ can upregulate phosphorylation of FoxO4. FoxO4 which is located in the nucleus is limited into the cytoplasm and inactivated; it loses the ability to suppress NF- $\kappa \mathrm{B}$ activity, it downregulates the expression of tight junction proteins and increases epithelial permeability. Disruption of the intestinal barrier allows endotoxin and other bacterial products in the gut lumen to pass into the portal circulation and cause hepatic inflammation. At the same time, the changes of liver injury deteriorate.

\section{Introduction}

Alcohol consumption is associated with the development of various medical disorder such as alcoholic liver disease (ALD) and pancreatitis. Several studies have found that short-term excessive drinking is more common than alcohol addiction and a dose-effect relationship between liver injury and alcohol is not always present; the environment and genetics also play a crucial role in ALD pathogenesis $(1,2)$. Intestinal barrier appears to be significantly involved in the initiation of alcoholinduced tissue damage and its role is more evident in liver injury. Disruption of the intestinal barrier allows endotoxin and other bacterial products in the gut lumen to pass into the portal circulation and cause hepatic inflammation and development of alcoholic steatohepatitis (ASH), which could lead to alcoholic cirrhosis and liver failure, which is a causal factor in the development of alcoholic endotoxemia and hepatitis. Keshavarzian et al (3) found that only alcoholics with liver disease have intestinal barrier dysfunction. The present study was undertaken to determine the role of FoxO4 in the relationship between alcohol in the intestinal barrier and liver injury.

The intestinal barrier is formed by the epithelial cells and tight junctions $(4,5)$. The intestinal epithelium provides barrier functions between the luminal triggers and the host. Intestinal barrier dysfunction could lead to increased uptake of luminal antigens that promote mucosal inflammation.

Increasing evidence suggests that Forkhead box 'Other' (FoxO) proteins, a subgroup of the Forkhead transcription factor family, have an important role in mediating the effects of 
insulin and growth factors on diverse physiological functions, including cell proliferation, apoptosis and metabolism, as well as on regulation of the immune response (6-13). Prevention of FoxO phosphorylation by AKT in response to growth factors such as platelet-derived growth factors (PDGF) and insulinlike growth factor 1 (IGF-1) has been reported. FoxO4 is a member of the FoxO subfamily that also includes FoxO1, FoxO3 and FoxO6 (14). FoxO4 can also be phosphorylated by phosphatidylinositol-3-kinase/AKT signaling resulting in its inactivation and nuclear exclusion $(15,16)$. The individual members of the FoxO family have unique cell type-specific functions and their regulation of target genes is context-dependent $(12,13)$. However, it remains to be determined whether FoxO4 has a similar immunoregulatory activity and whether FoxO4 has a role in the relationship between alcohol-induced intestinal barrier dysfunction and liver injury.

In this study, we investigated the role of FoxO4 in ALD using an animal model. We found that FoxO4 is an interacting factor which forms a complex that represses tumor necrosis factor $\alpha(\mathrm{TNF} \alpha)$ transcriptional activation of nuclear factor- $\kappa \mathrm{B}$ $(\mathrm{NF}-\kappa \mathrm{B})$ in the ALD animals. Furthermore, it protects the intestinal barrier from the alcohol by increasing the expression of tight junction proteins.

\section{Materials and methods}

Rats, alcohol treatment. Six to eight-week-old littermates or age-matched male WT rats $(200 \pm 10 \mathrm{~g}$ at intake) were obtained from the Experiment Animal Center, China Medical University. All rats in the study were used strictly in accordance with the National Institution of Health Guide for the Care and Use of Laboratory Animals. Our study received the approval of the China Medical University Animal Committee (no. 2011-1538).

Rats were deprived of food for $12 \mathrm{~h}$ prior to induction of acute alcoholic liver injury. During the experiments, the rats were divided into eight groups.

In the control group, eight rats were treated twice daily with corn starch alone dissolved in $200 \mu \mathrm{l}$ of PBS and administered via gastric tube.

In the alcohol group, eight rats were given $40 \%$ alcohol ( $5 \mathrm{~g} / \mathrm{kg}$ body weight) through stomach feeding every $12 \mathrm{~h} /$ time, three times in total.

In the $\mathrm{TNF} \alpha$, the wortmannin (an AKT signaling inhibitor) and the IGF-1 group (an AKT signaling agonist) rats were separately injected intraperitoneally with $\mathrm{TNF} \alpha(10 \mu \mathrm{g} / \mathrm{kg}$ body weight), wortmannin (1.4 $\mathrm{mg} / \mathrm{kg}$ body weight) or IGF-1 ( $0.2 \mathrm{mg} / \mathrm{kg}$ body weight) $30 \mathrm{~min}$ before alcohol administration.

In the anti-TNF $\alpha$ group, anti-TNF $\alpha$ ( $5 \mathrm{mg} / \mathrm{kg}$ body weight $)$ was injected intravenously into alcohol-treated rats $30 \mathrm{~min}$ before alcohol administration.

In the two placebo groups, rats were treated with PBS injected either intraperitoneally or intravenously prior to induction of alcohol liver injury. The small intestine and liver of all rats were swiss-rolled, formalin-fixed and paraffin-embedded.

Assessment of tight junction proteins of small intestine by electron microscopy. A standard fixation procedure was used for conventional thin section electron microscopy. The procedure involved incubation with $\mathrm{OsO}_{4}$ alone (1 or $2 \%$ in phosphate buffer) at $0^{\circ} \mathrm{C}$ for $30 \mathrm{~min}$. After fixation, the small intestine was washed extensively in Veronal acetate buffer (90 mm, pH 6.0), stained by incubation at $0^{\circ} \mathrm{C}$ for $60 \mathrm{~min}$ in uranyl magnesium acetate $(0.5 \%)$ in the same buffer, washed again, dehydrated and embedded. Thin sections were cut at $60 \mathrm{~nm}$ with a diamond knife and stained with uranyl acetate and lead citrate for viewing on a $200 \mathrm{CX}$ transmission electron microscope at $80 \mathrm{kV}$. High-magnification images (x10,000) were captured to evaluate the ultrastructure of tight junctions in small intestine tissue.

Immunohistochemistry. Paraffin slides were deparaffinized and rehydrated, deparaffinized in xylene I, II and III for $10 \mathrm{~min}$, dehydrated in 95, 90 and 70\% ethanol for $2 \mathrm{~min}$, and then tissue sections were rinsed three times for $5 \mathrm{~min}$ each in $0.01 \mathrm{~mol} / 1$ phosphate-buffered saline (PBS, pH 7.4), preincubated for $15 \mathrm{~min}$ with $0.3 \% \mathrm{H}_{2} \mathrm{O}_{2}$, and then pre-incubated for $15 \mathrm{~min}$ with $5 \%$ normal goat serum and incubated overnight at $4^{\circ} \mathrm{C}$ with rabbit anti-FoxO4 polyclonal antibody (rabbit anti-rat, 1:400). After rinsing with $0.01 \mathrm{~mol} / \mathrm{l} \mathrm{PBS}$, sections were incubated for $15 \mathrm{~min}$ with secondary goat anti-rabbit immunoglobulin $\mathrm{G}$ at $37^{\circ} \mathrm{C}$, rinsed three times for $5 \mathrm{~min}$ each in $0.01 \mathrm{~mol} / 1 \mathrm{PBS}$, incubated for $15 \mathrm{~min}$ with tertiary antibody at $37^{\circ} \mathrm{C}$, and rinsed $3 \times 5 \mathrm{~min}$ in $0.01 \mathrm{~mol} / 1 \mathrm{PBS}$. A peroxidase reaction was performed to visualize FoxO4 immunolabeling by incubating with $0.05 \%$ 3,3-diaminobenzidine tetrahydrochloride for $3 \mathrm{~min}$ and stopping the reaction with $0.01 \mathrm{~mol} / \mathrm{l} \mathrm{PBS}$. To assess antibody specificity, incubation with the primary antibody was omitted for some sections and no significant staining was observed in this case. Positive results showed brown and dark brown. Similarly, tissue sections were incubated overnight at $4{ }^{\circ} \mathrm{C}$ with rabbit anti-p-FoxO4 polyclonal antibody (rabbit anti-rat, 1:400), and were then stained by the same immunohistochemical method.

Measurement of TNF $\alpha$, endotoxin, ALT and AST in plasma. $\mathrm{TNF} \alpha$ levels in the media were assessed using a rat TNF $\alpha$ ELISA set according to the manufacturer's instructions. TNF $\alpha$ concentrations were determined using a standard and values were normalized to total DNA present in the well using a DNA quantification kit. Endotoxin was measured by Tachypleus Amebocye Lysate. ALT and AST were measured by biochemical methods.

Western blot analysis. Using snap-frozen small intestine specimens with histologically intact epithelium, we stripped the mucosa from the underlying submucosal tissue, homogenized and sonicated it, and transferred it into ice-cold lysis buffer with a protease inhibitor cocktail for $60 \mathrm{~min}$. Lysates were centrifuged and the protein content of the supernatant was determined by using the BCA protein assay kit. Depending on the antibody used, equivalent protein concentrations of 10-75 lg were loaded onto each lane of SDS-polyacrylamide gels. Electrophoretically separated samples were transferred to an immobilon transfer membrane. Membranes were incubated with the respective primary antibodies and a corresponding peroxidase-conjugated secondary antibody. Blots were visualized by chemiluminescence using immobilon Western Chemiluminescent HRP substrate. After detection of specific tight junctions, FoxO4 and p-FoxO4, all membranes were 

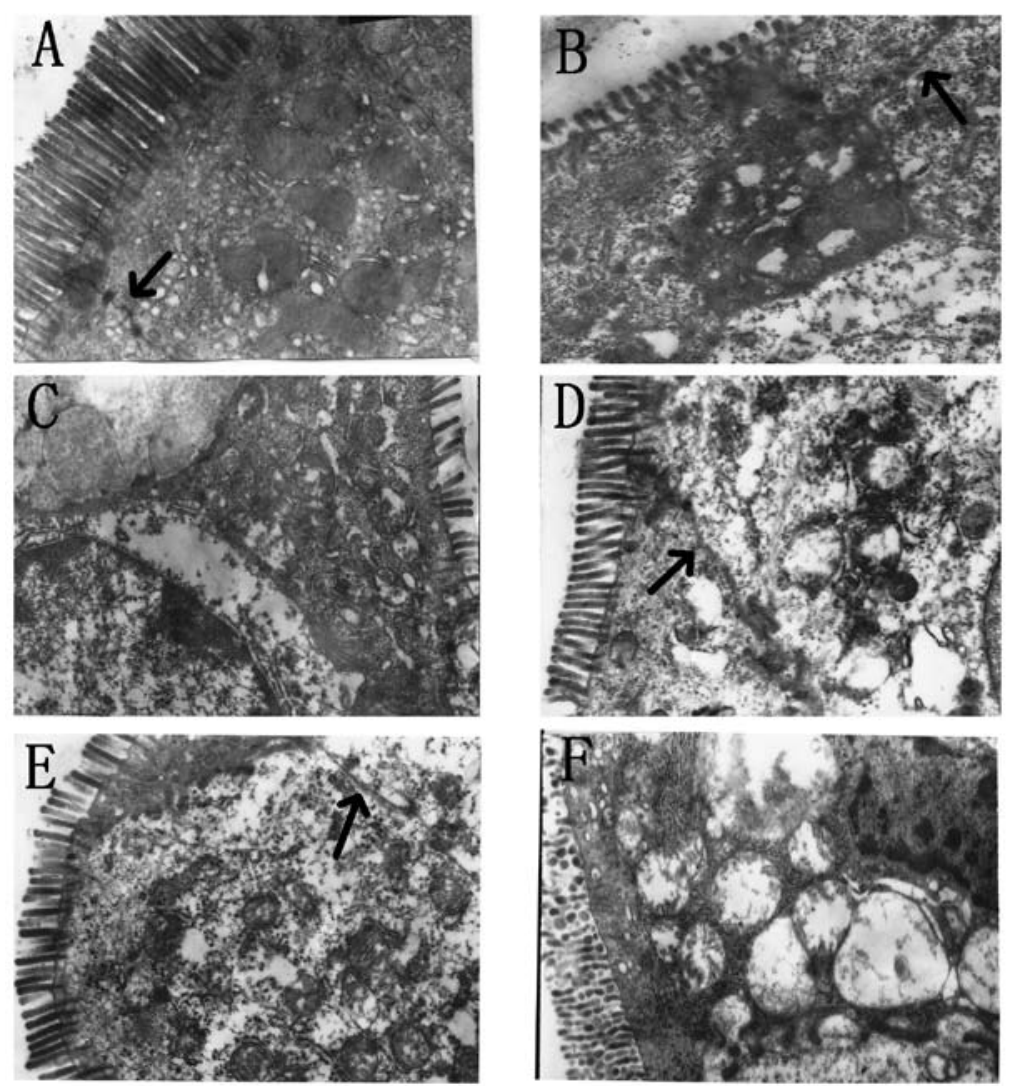

Figure 1. (A) Control group (x10,000); tight junctions in the small intestine were visualized (arrow), and in free surface, microvilli were arranged neatly and intensively. (B) Alcohol group (x10,000); alcohol administration significantly disrupted the tight junctions of the small intestine (arrow), and microvilli became short and partly missing. (C) TNFo group (x10,000); tight junctions were seriously disrupted and could not be found under electron microscopy, microvilli became shorter and fewer than in the alcohol group. (D) Anti-TNFa group (x10,000); tight junctions could be found under microscopy (arrow) and microvilli were normal. (E) Wortmannin group (x10,000); tight junctions could be found under microscopy (arrow) and microvilli were normal. (F) IGF-1 group (x10,000); tight junctions were seriously disrupted and could not be found under electron microscopy, microvilli became shorter and fewer than in the alcohol group.

stripped with Restore Western Blot Stripping Buffer, and an immunoblot for $\beta$-actin was performed to ensure equal protein loading in each lane. Densitometry was performed for each detected protein in each group.

RNA isolation and reverse transcription-polymerase chain reaction. The plasmids were cloned using PCR. RNA extraction, reverse transcription-polymerase chain reaction (RT-PCR), and microarray. The following primerpairs were used for amplification: occludin, sense, 5'-GCTATGAAACCGACTACACGACA-3'; and antisense, 5'-ACTCTCCAGCAACCAGCATCT-3'; ZO-1, sense, 5'-AGGCTATTTCCAGCGTTTTGA-3' and antisense, 5'-AA TCCTGGTGGTGGTACTTGC-3'; NF-кB, sense, 5'-CGCAT TCTGACCTTGCCTATC-3' and antisense, 5'-AGTCCAGTC TCCGAGTGAAGC-3'.

Statistical analysis. All data are expressed as the means \pm SD and were analyzed using one-way analysis of variance. $\mathrm{P}<0.05$ was considered to indicate statistically significant differences.

\section{Results}

The expression of tight junctions under electron microscopy. We studied tight junctions in small intestine using electron microscopy as an index of loss of colonic barrier integrity. Acute alcohol administration significantly disrupted the architecture of the tight junctions of the small intestine. Wortmannin and anti-TNF $\alpha$ supplementation significantly protected the cytoarchitecture of the intestinal barrier. However, in the TNF $\alpha$ and IGF-1 groups, different degrees of tight junctions injured were observed (Fig. 1).

The expression of TNF $\alpha$ and endotoxin. We examined the expression of TNF $\alpha$ in plasma in the eight groups using ELISA. Compared with the control group $(175.51 \pm 11.205)$, the expression of TNF $\alpha$ was higher in the alcohol group (383.95 \pm 18.231$)$. In the TNFa $(448.91 \pm 31.447)$ and the IGF-1 group $(455.00 \pm 27.917)$ the expression was significantly higher than in the alcohol group. However, its expression in the wortmannin $(220.08 \pm 13.794)$ and the anti-TNF $\alpha$ group $(229.10 \pm 24.027)$ was significantly lower than that in the alcohol group (Fig. 2).

We examined the expression of endotoxin in the eight groups by Tachypleus Amebocye Lysate. We found that the expression of endotoxin was higher in the alcohol group $(1.59 \pm 0.081)$ compared with the control group $(0.25 \pm 0.091)$. In the TNF $\alpha$ $(2.11 \pm 0.147)$ and the IGF-1 group $(2.13 \pm 0.126)$ the levels were significantly higher in the alcohol group. However, its expression in the wortmannin $(0.77 \pm 0.144)$ and the anti-TNF $\alpha$ group $(0.90 \pm 0.113)$ was significantly lower than that in the alcohol group (Fig. 3). 


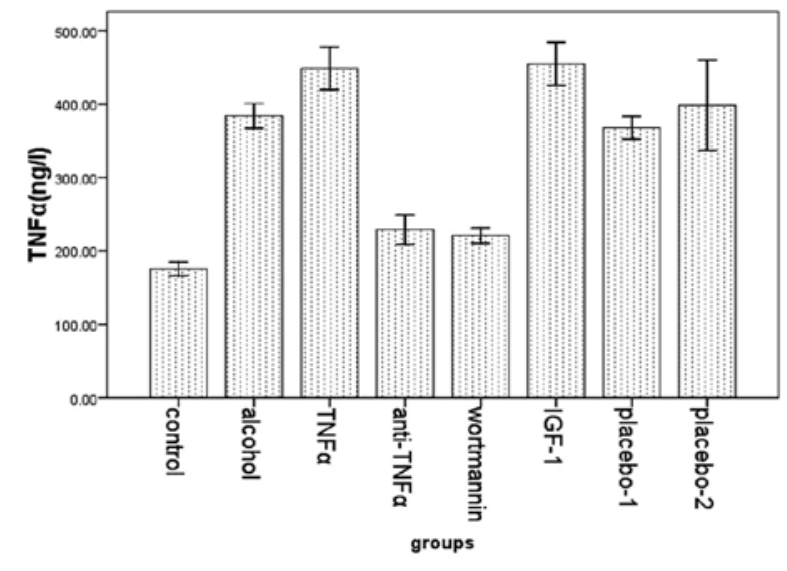

Figure 2. The expression of TNF $\alpha$ in each group measured by ELISA.

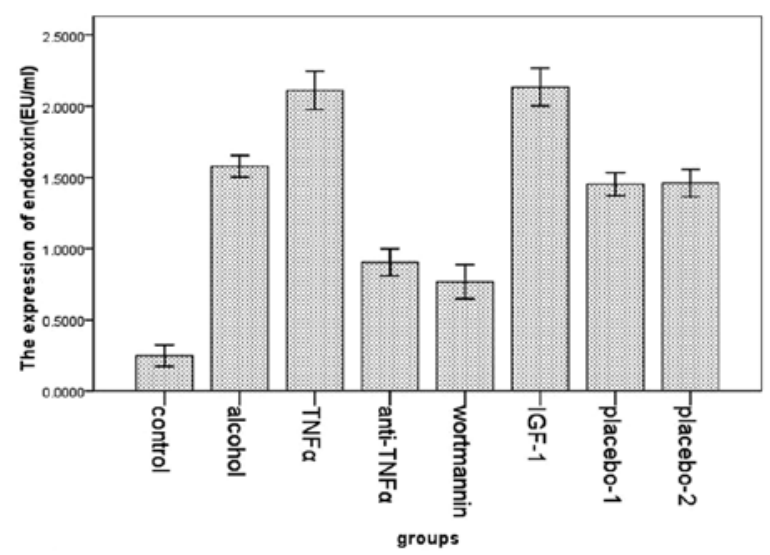

Figure 3. The expression of endotoxin in each group measured by Tachypleus Amebocye Lysate.

The expression of ALT and AST. We examined the expression of ALT and AST in plasma in the eight groups. Compared with the control group $(37.875 \pm 9.188 ; 107.875 \pm 15.292)$, the expression of ALT and AST was higher in the alcohol group $(122.143 \pm 23.061 ; 253.714 \pm 25.031)$. In the $\mathrm{TNF} \alpha$ $(144.000 \pm 19.732 ; 293.571 \pm 21.259)$ and the IGF-1 group $(146.500 \pm 17.852 ; 295.167 \pm 18.957)$ the expression levels were significantly higher than in the alcohol group. However, its expression in the wortmannin $(62.250 \pm 10.068$; $160.625 \pm 18.213)$ and the anti-TNF $\alpha$ group $(61.750 \pm 12.669$; $156.000 \pm 19.893)$ was significantly lower than that in the alcohol group (Fig. 4).

The expression and distribution of FoxO4 and p-FoxO4. In order to examine the role of FoxO4 in protein expression and distribution of tight junction proteins, we first used immunohistochemistry. During PKB/AKT activation (in the TNF $\alpha$ and IGF-1 groups), FoxO4 became phosphorylated, upregulated and was excluded into the cytoplasm (Fig. 5).

To extend our observations of changes of FoxO4 and p-FoxO4 expression, the two proteins were analyzed by western blotting in the small intestine of the eight groups. There were no differences in the expression of FoxO4 among the eight groups. By contrast, the expression of p-FoxO4 was

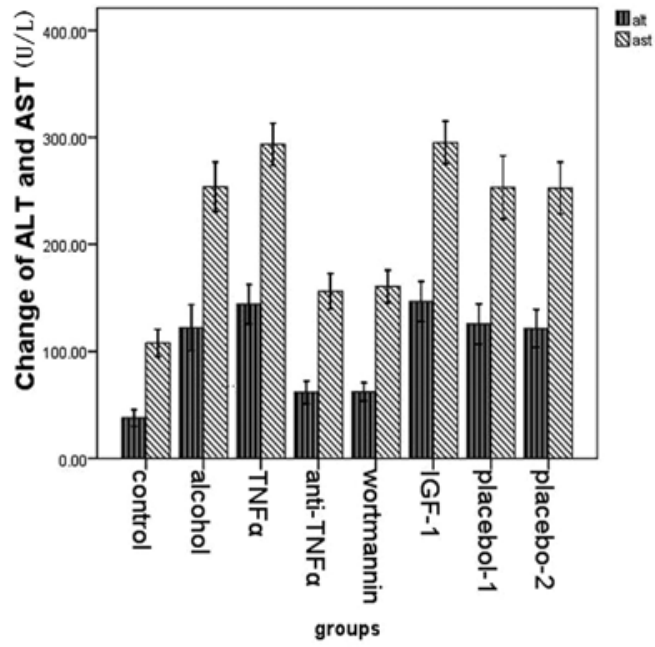

Figure 4. The expression of ALT and AST in each group measured by biochemical method.
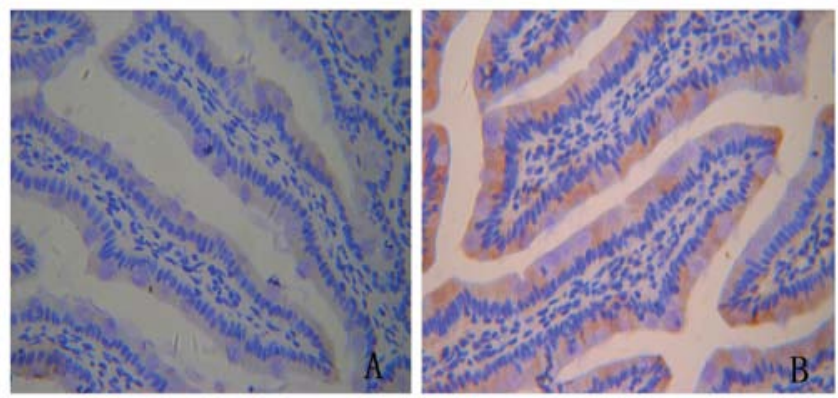

Figure 5. (A) Immunohistochemistry for p-FoxO4 dephosphorylated in small intestine membrane (x20). (B) Immunohistochemistry for p-FoxO4 phosphorylated in small intestine membrane (x20).

markedly different among the eight groups. Compared with rats in the alcohol group $(0.621 \pm 0.104)$, significant reductions in total protein for $\mathrm{p}-\mathrm{FoxO} 4$ were observed in rats in the control $(0.099 \pm 0.046)$, the wortmannin $(0.224 \pm 0.084)$ and the anti-TNF $\alpha$ group $(0.287 \pm 0.064)$. The p-FoxO4 expression in rats in the TNF $\alpha(0.796 \pm 0.137)$ and the IGF-1 group $(0.831 \pm 0.104)$ were significantly higher than in the alcohol group (Figs. 6 and 7).

The expression of $N F-\kappa B$ and tight junction proteins. To observe the striking changes of NF- $\mathrm{KB}$ and tight junction protein expression, the expression levels were analyzed by western blotting and RT-PCR in the small intestine of the eight groups.

First, the trend of NF- $\mathrm{KB}$ was consistent with the changes of $\mathrm{p}$-FoxO4. Compared with rats in the alcohol group $(0.467 \pm 0.057,0.269 \pm 0.047)$, significant reductions in total protein and mRNA for NF- $\mathrm{kB}$ were observed in rats in the control $(0.174 \pm 0.033,0.109 \pm 0.017)$, the wortmannin $(0.244 \pm 0.045,0.168 \pm 0.031)$ and in the anti-TNF $\alpha$ group $(0.283 \pm 0.039,0.167 \pm 0.027)$. NF- $\kappa \mathrm{B}$ expression in rats in the TNF $\alpha(0.578 \pm 0.071,0.442 \pm 0.038)$ and the IGF-1 group $(0.559 \pm 0.080,0.440 \pm 0.033)$ were significantly higher than in the alcohol group (Figs. 8-11). 


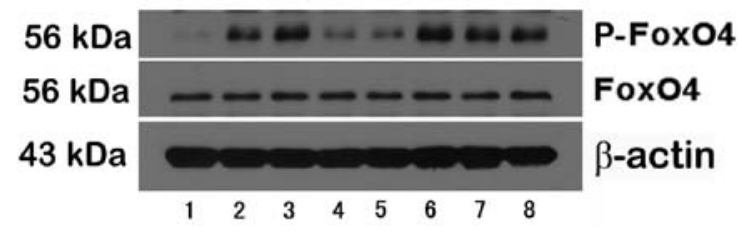

Figure 6. Western blot analysis of FoxO4 and p-FoxO4. 1, Control group; 2 , alcohol group; $3, \mathrm{TNF} \alpha$ group; 4 , anti-TNF $\alpha$ group; 5 , wortmannin group; 6, IGF-1 group; 7, placebo-1 group; 8 , placebo-2 group.
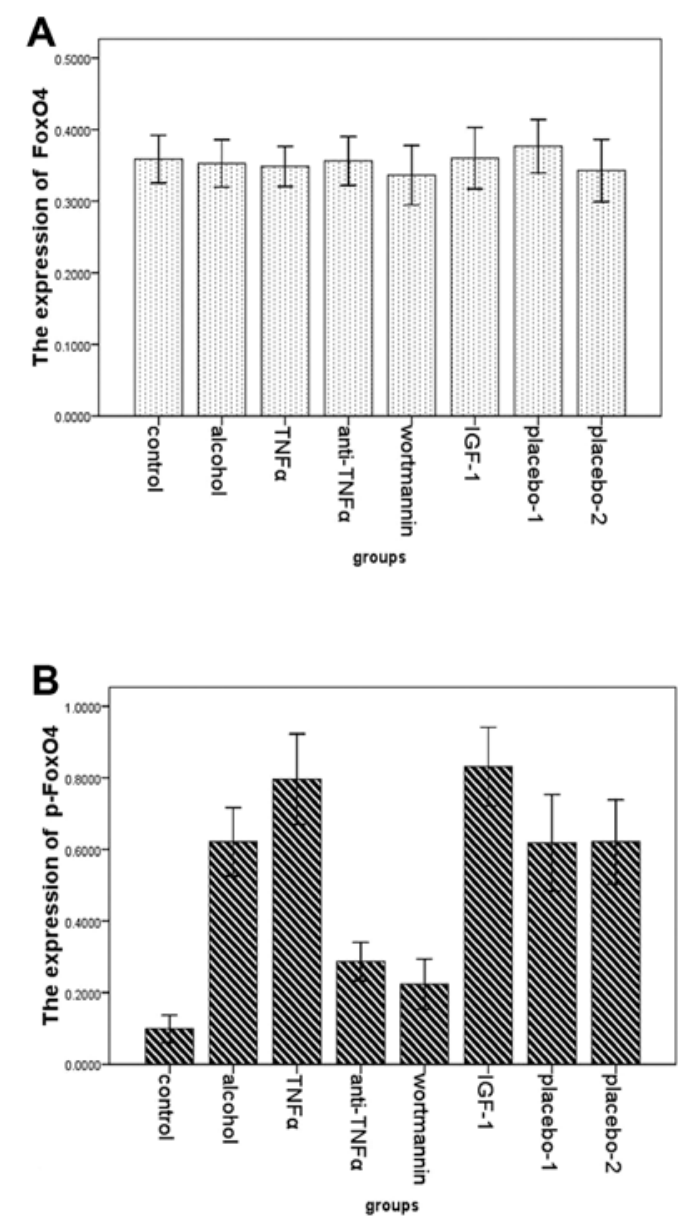

Figure 7. Western blot densitometry of (A) FoxO4 and (B) p-FoxO4 in each group. Immunoblots for $\beta$-actin were performed for each membrane to normalize epithelial protein loading between samples.

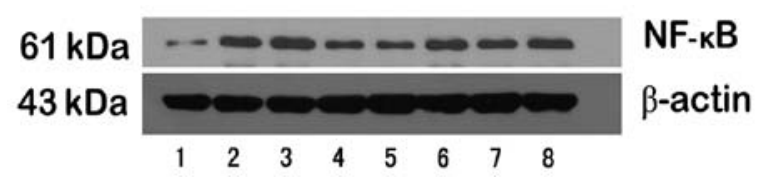

Figure 8. Western blot analysis of NF-кB. 1, Control group; 2, alcohol group 3 , TNF $\alpha$ group; 4, anti-TNF $\alpha$ group; 5, wortmannin group; 6, IGF-1 group; 7, placebo-1 group; 8, placebo-2 group.

Second, the trend of tight junction proteins was reversed with the change of NF- $\mathrm{KB}$. Thus, in the alcohol group (occludin, 0.305 \pm 0.949 , ZO-1, 0.379 \pm 0.097 ; occludin mRNA, $0.630 \pm 0.114$; ZO-1 mRNA, 1.109 \pm 0.172 ), the expression of protein and mRNA for occludin and ZO-1 were markedly

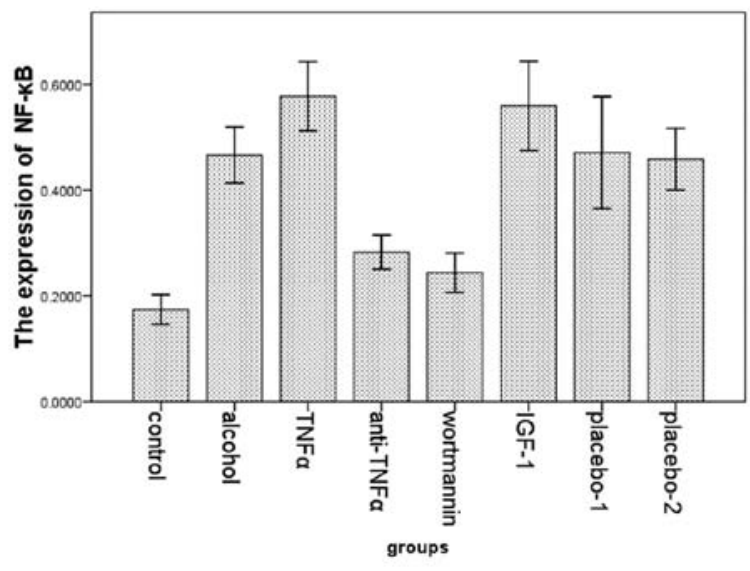

Figure 9. Western blot densitometry of NF- $\mathrm{BB}$ in each group.
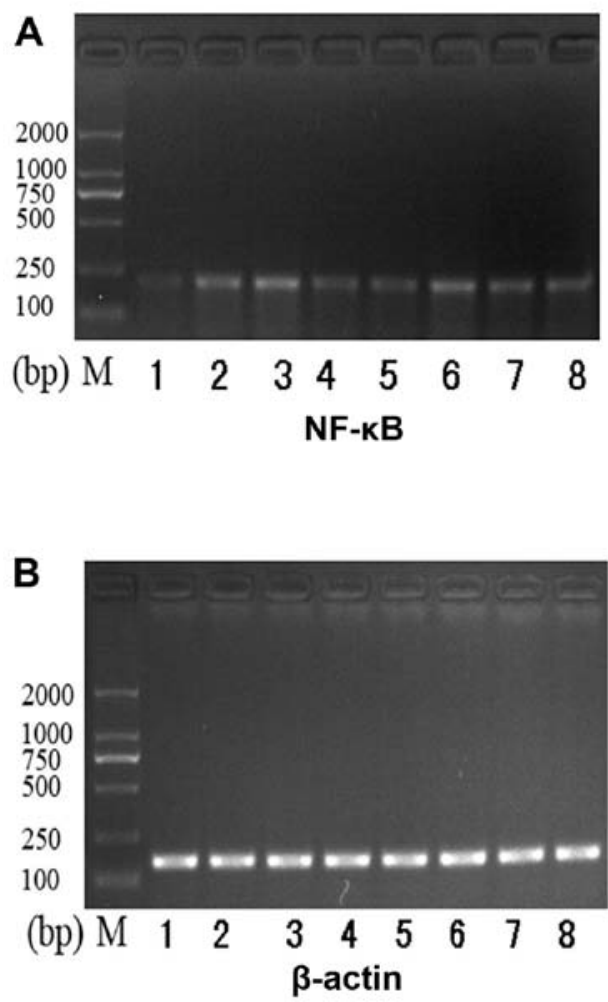

Figure 10. RT-PCR of NF-кB. 1, Control group; 2, alcohol group; 3, TNFo group; 4, anti-TNF $\alpha$ group; 5, wortmannin group; 6 , IGF-1 group; 7, placebo-1 group; 8 , placebo-2 group.

lower than in the control group (occludin, $0.838 \pm 0.166$, ZO- 1 , $1.029 \pm 0.145$; occludin mRNA, $1.38 \pm 0.140$, ZO-1 mRNA, $1.990 \pm 0.136$ ), in the wortmannin group (occludin, $0.634 \pm 0.156$, ZO-1, 0.841 \pm 0.109 ; occludin mRNA, $1.168 \pm 0.061$, ZO-1 mRNA, $1.715 \pm 0.191$ ) and in the anti-TNF $\alpha$ group (occludin, $0.536 \pm 0.100, \mathrm{ZO}-1,0.748 \pm 0.163$; occludin mRNA, $1.073 \pm 0.153$, ZO-1 mRNA, 1.665 \pm 0.125$)$. However, in the TNF $\alpha$ group (occludin, 0.176 \pm 0.078 , ZO-1, 0.200 \pm 0.069 ; occludin mRNA, $0.441 \pm 0.077, \mathrm{ZO}-1 \mathrm{mRNA}, 0.754 \pm 0.096)$ and the IGF-1 group (occludin, $0.177 \pm 0.036$, ZO-1, $0.201 \pm 0.082$; occludin mRNA, $0.425 \pm 0.106, \mathrm{ZO}-1 \mathrm{mRNA}, 0.720 \pm 0.101$ ) they were significantly lower than those in the alcohol group (Figs. 12-15). 


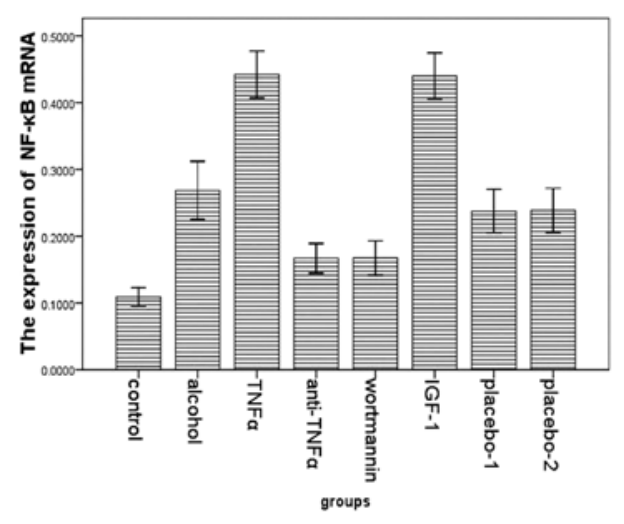

Figure 11. PCR densitometry of tight NF-kB in each group.

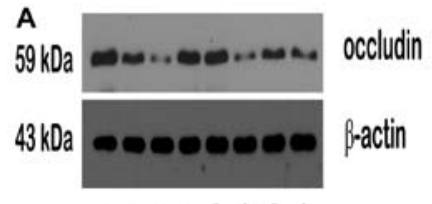

12345678

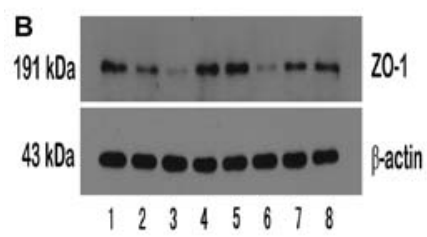

Figure 12. Western blot analysis of tight junction proteins (A) occludin and (B) ZO-1. 1, Control group; 2, alcohol group; 3, TNFa group; 4, anti-TNF $\alpha$ group; 5, wortmannin group; 6, IGF-1 group; 7, placebo-1 group; 8, placebo-2 group.
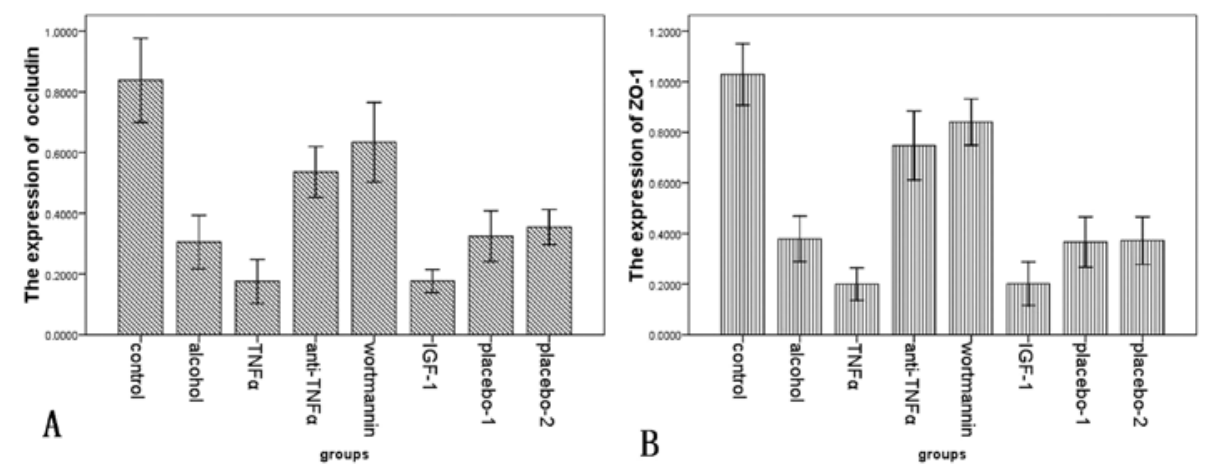

Figure 13. Western blot densitometry of tight junction proteins (A) occludin and (B) ZO-1 in each group. Immunoblots for $\beta$-actin were performed for each membrane to normalize epithelial protein loading between samples.
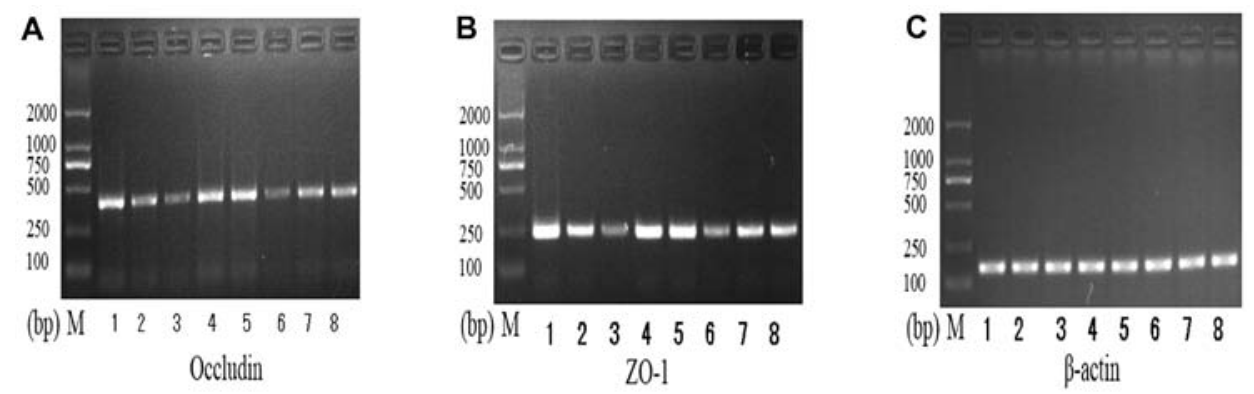

Figure 14. RT-PCR of tight junction proteins (occludin and ZO-1). 1, Control group; 2, alcohol group; 3, TNF $\alpha$ group; 4, anti-TNF $\alpha$ group; 5, wortmannin group; 6, IGF-1 group; 7, placebo-1 group; 8, placebo-2 group.
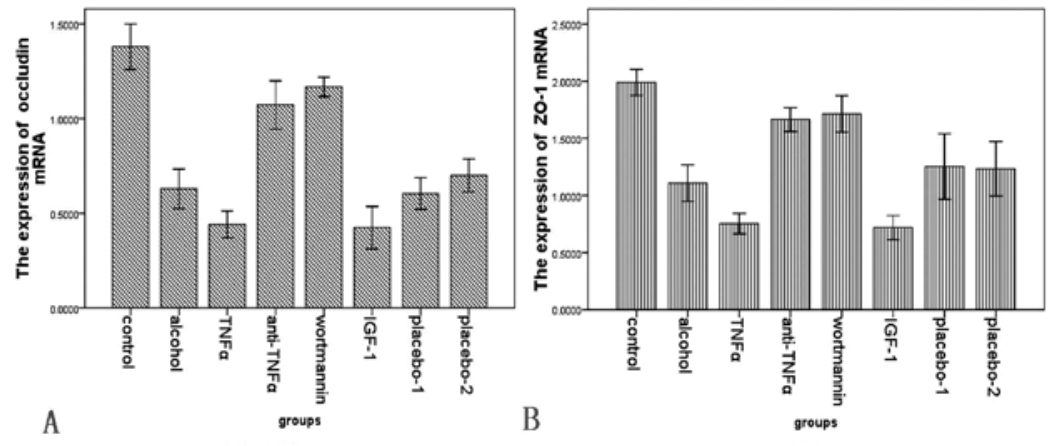

Figure 15. PCR densitometry of tight junction proteins (A) occludin mRNA and (B) ZO-1 mRNA in each group. 


\section{Discussion}

In the present study, we investigated the mechanisms by which FoxO4 regulates epithelial permeability, tight junction protein expression and liver damage in a rat model of acute alcohol liver disease.

Our results showed that the impairment of intestinal barrier function in acute alcohol liver disease is associated with loss of the tight junction proteins, including occludin and ZO-1. Tight junctions are the major determinants of paracellular permeability. Although changes in epithelial tight junction protein expression have been studied extensively in monolayers stimulated by cytokines, challenged by bacteria, or exposed to aspirin (17-23), much remains to be understood about barrier disruptive changes under acute alcohol consumption.

FoxO4 may regulate intestinal permeability through tight junction proteins. Expression levels and distribution of these tight junction proteins may influence the epithelial permeability $(4,5,24,25)$. Previous studies have shown that downregulation of ZO-1 and claudin-1 in both FoxO4-deficient epithelial cells in vivo and FoxO4-knocked down epithelial cells in vitro, could provide a structural basis for the increased intestinal epithelial permeability in FoxO4-null mice (26).

The effects of FoxO4 on epithelial permeability are likely through NF- $\mathrm{kB}$ (26-30). Both loss and gain-of function of NF- $\kappa \mathrm{B}$ have been shown to increase epithelial permeability through different mechanisms. Nenci et al (30) showed that $\mathrm{NF}-\kappa \mathrm{B}$ inactivated epithelial cells have increased permeability due to an increase in TNF $\alpha$-mediated epithelial cell death. Upregulation of epithelial permeability in FoxO4-null mice is likely due to the downregulation of tight junction proteins as a result of increased NF- $\mathrm{KB}$ activity in the epithelial cells. FoxO4 could inactivate NF- $\mathrm{KB}$ through direct physical interaction; however, when FoxO4 becomes phosphorylated, it loses the ability to restrain NF- $\mathrm{kB}$, resulting in the downregulation of tight junction proteins and an increase in epithelial permeability (26).

Our results showed that, first, when TNF $\alpha$ increased, FoxO4 became phosphorylated and was excluded into cytoplasm. The expression of p-FoxO4 increased and at the same time $\mathrm{NF}-\kappa \mathrm{B}$ became active and tight junction proteins decreased. Then, when the rats were given anti-TNFa, the expression of $\mathrm{TNF} \alpha$ decreased, FoxO4 became dephosphorylated, active and located in nucleolus, and at the same time NF- $\mathrm{kB}$ became inactive and tight junction proteins increased. Subsequently, when the rats were given wortmannin, which is an AKT signaling inhibitor, FoxO4 became dephosphorylated, active and located in nucleolus, and at the same time NF- $\kappa$ B became inactive and tight junction proteins increased. Finally, when the rats were given IGF-1, an AKT signaling agonist, FoxO4 became phosphorylated and was excluded into the cytoplasm, the expression of p-FoxO4 increased, at the same time NF- $\mathrm{KB}$ became active and tight junction proteins decreased. As a result, the intestinal bacteria grew excessively, endotoxin was released into portal circulation and liver injury deteriorated.

In summary, our findings suggest a complex network of mechanisms involved in the beneficial effects of FoxO4 in the epithelial barrier dysfunction. We demonstrated that TNFa can upregulate phosphorylation of FoxO4. FoxO4, which is located in the nucleus, is then excluded into the cytoplasm and inactivated, it loses the ability to restrain NF- $\mathrm{KB}$ activity, and then downregulates the expression of tight junction proteins and increases epithelial permeability. At the same time, the endotoxin was released into portal circulation, and liver injury deteriorated.

\section{Acknowledgements}

The authors thank all the participants in the present study and they also thank Miss. Cheng for her editorial assistance.

\section{References}

1. Stewart S, Jones D and Day CP: Alcoholic liver disease: new insights into mechanisms and preventative strategies. Trends Mol Med 7: 408-413, 2001.

2. Rouault TA: Hepatic iron overload in alcoholic liver disease: why does it occur and what is its role in pathogenesis? Alcohol 30: 103-106, 2003.

3. Keshavarzian A, Holmes EW, Patel M, et al: Leaky gut in alcoholic cirrhosis: a possible mechanism for alcohol-induced liver damage. Am J Gastroenterol 94: 200-207, 1999.

4. Ma TY, Iwamoto GK, Hoa NT, et al: TNF-alpha-induced increase in intestinal epithelial tight junction permeability requires NF-kappa B activation. Am J Physiol Gastrointest Liver Physiol 286: G367-G376, 2004.

5. Ma TY and Anderson JM: Tight junctions and intestinal barrier. In: Physiology of the Gastrointestinal Tract. Johnson LR (ed). Elsevier Academic Press, New York, NY, pp1559-1594, 2006.

6. Marchetti V, Menghini R, Rizza S, et al: Benfotiamine counteracts glucose toxicity effects on endothelial progenitor cell differentiation via Akt/FoxO signaling. Diabetes 55: 2231-2237, 2006.

7. Essaghir A, Dif N, Marbehant CY, et al: The transcription of FOXO genes is stimulated by FOXO3 and repressed by growth factors. J Biol Chem 284: 10334-10342, 2009.

8. Liu ZP, Wang Z, Yanagisawa $\mathrm{H}$ and Olson EN: Phenotypic modulation of smooth muscle cells through interaction of FoxO4 and myocardin. Dev Cell 9: 261-270, 2005.

9. Burgering BM: A brief introduction to FOXOlogy. Oncogene 27: 2258-2262, 2008.

10. Lin L, Hron JD and Peng SL: Regulation of NF-kappaB, Th activation and autoinflammation by the forkhead transcription factor Foxo3a. Immunity 21: 203-213, 2004.

11. Dengler HS, Baracho GV, Omori SA, et al: Distinct functions for the transcription factor Foxol at various stages of B cell differentiation. Nat Immunol 9: 1388-1398, 2008.

12. Paik JH, Kollipara R, Chu G, et al: FoxOs are lineage-restricted redundant tumor suppressors and regulate endothelial cell homeostasis. Cell 128: 309-323, 2007.

13. Tothova Z, Kollipara R, Huntly BJ, et al: FoxOs are critical mediators of hematopoietic stem cell resistance to physiologic oxidative stress. Cell 128: 325-339, 2007.

14. Birkenkamp KU and Coffer PJ: Regulation of cell survival and proliferation by the FOXO (Forkhead box, class O) subfamily of Forkhead transcription factors. Biochem Soc Trans 31: 292-297, 2003.

15. Lüpertz R, Chovolou Y, Unfried K, et al: The forkhead transcription factor $\mathrm{FOXO} 4$ sensitizes cancer cells to doxorubicin-mediated cytotoxicity Carcinogenesis 29: 2045-2052, 2008.

16. Matsuzaki H, Ichino A, Hayashi T, et al: Regulation of intracellular localization and transcriptional activity of FOXO4 by protein kinase B through phosphorylation at the motif sites conserved among the FOXO family. J Biochem 138: 485-491, 2005.

17. Anderson RC, Cookson AL, McNabb WC, et al: Lactobacillus plantarum MB452 enhances the function of the intestinal barrier by increasing the expression levels of genes involved in tight junction formation. BMC Microbiol 10: 316, 2010.

18. Donato KA, Gareau MG, Wang YJ and Sherman PM: Lactobacillus rhamnosus GG attenuates interferon-(gamma) and tumour necrosis factor-alpha-induced barrier dysfunction and pro-inflammatory signalling. Microbiology 156: 3288-3297, 2010.

19. Ewaschuk JB, Diaz H, Meddings L, et al: Secreted bioactive factors from Bifidobacterium infantis enhance epithelial cell barrier function. Am J Physiol Gastrointest Liver Physiol 295: G1025-G1034, 2008. 
20. Karczewski J, Troost FJ, Konings I, et al: Regulation of human epithelial tight junction proteins by Lactobacillus plantarum in vivo and protective effects on the epithelial barrier. Am J Physiol Gastrointest Liver Physiol 298: G851-G859, 2010.

21. Mennigen R, Nolte K, Rijcken E, et al: Probiotic mixture VSL\#3 protects the epithelial barrier by maintaining tight junction protein expression and preventing apoptosis in a murine model of colitis. Am J Physiol Gastrointest Liver Physiol 296 : G1140-G1149, 2009.

22. Resta-Lenert S and Barrett KE: Live probiotics protect intestinal epithelial cells from the effects of infection with enteroinvasive Escherichia coli (EIEC). Gut 52: 988-997, 2003.

23. Zyrek AA, Cichon C, Helms S, et al: Molecular mechanisms underlying the probiotic effects of Escherichia coli Nissle 1917 involve $\mathrm{ZO}-2$ and PKCzeta redistribution resulting in tight junction and epithelial barrier repair. Cell Microbiol 9: 804-816, 2007.

24. Ye D, Ma I and Ma TY: Molecular mechanism of tumor necrosis factor-alpha modulation of intestinal epithelial tight junction barrier. Am J Physiol Gastrointest Liver Physiol 290: G496-G504 2006.
25. Atreya I, Atreya R and Neurath MF: NF-kappaB in inflammatory bowel disease. J Intern Med 263: 591-596, 2008.

26. Zhou W, Cao Q, Peng Y, Zhang QJ, et al: FoxO4 inhibits NF-kappaB and protects mice against colonic injury and inflammation. Gastroenterology 137: 1403-1414, 2009.

27. Andresen L, Jørgensen VL, Perner A, et al: Activation of nuclear factor kappaB in colonic mucosa from patients with collagenous and ulcerative colitis. Gut 54: 503-509, 2005.

28. Montufar-Solis D, Garza T and Klein JR: T-cell activation in the intestinal mucosa. Immunol Rev 215: 189-201, 2007.

29. Gadjeva M, Wang Y and Horwitz BH: NF-kappaB p50 and p65 subunits control intestinal homeostasis. Eur J Immunol 37: 2509-2517, 2007.

30. Nenci A, Becker C, Wullaert A, et al: Epithelial NEMO links innate immunity to chronic intestinal inflammation. Nature 446 : 557-561, 2007. 